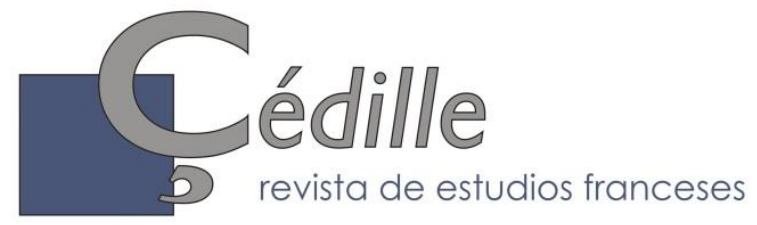

\title{
La recepción de tres novelas de George Sand en Es- paña a través de sus ediciones y (re)traducciones
}

\author{
Caterina RIBA \\ Carme SANMARTí \\ Universitat de Vic - Universitat Central de Catalunya \\ caterina.riba@uvic.cat \\ ORCID: 0000-0001-9099-3648 \\ mcarme.sanmarti@uvic.cat \\ ORCID: 0000-0003-4354-0157
}

\section{Resumen}

Este artículo analiza las ediciones y retraducciones al español y al catalán de tres obras de la autora francesa George Sand (1804-1876): La mare au diable, Un hiver à Majorque y La petite Fadette. El estudio examina varios de los factores y agentes interrelacionados que condicionaron la trayectoria de las obras. Entre ellos, se analizan las consecuencias de la inclusión de la escritora en el Index Librorum Prohibitorum y el impacto de la censura franquista, la reivindicación de Sand por parte del movimiento feminista, el hecho de que se haya convertido en un reclamo turístico, las políticas editoriales que se han seguido y los principales retos de traducción.

Palabras clave: Traducción. Index Librorum Prohibitorum. Censura. La mare au diable. Un hiver à Majorque. La petite Fadette.

\section{Résumé}

Cet article analyse les éditions et les retraductions vers l'espagnol et le catalan de trois œuvres de George Sand (1804-1876) : La mare au diable, Un hiver à Majorque et La petite Fadette. L'étude examine quelques uns des facteurs et des agents interdépendants qui conditionnent la trajectoire des œuvres. Parmi eux, nous analysons les conséquences de l'inclusion de l'écrivaine dans l'Index Librorum Prohibitorum, l'impact de la censure franquiste, la revendication de l'auteure de la part du mouvement féministe, le fait qu'elle soit devenue une attraction touristique, les politiques éditoriales et les principaux défis de traduction.

Mots clé : Traduction. Index Librorum Prohibitorum. Censure. La mare au diable. Un hiver à Majorque. La petite Fadette.

\begin{abstract}
This article is an analysis of the Spanish and Catalan retranslations of three works by the French writer George Sand (1804-1876): La mare au diable, Un hiver à Majorque and La petite Fadette. This study looks both at various factors and at a number of interrelated individuals and groups, all of which played a role in determining the fate of these works. The analysis includes a look at the consequences of the inclusion of the author's works on the Index Librorum Prohibitorum and at the effects of the Franco regime's cen-
\end{abstract}

* Artículo recibido el 18/11/2019, aceptado el 15/10/2020. 
sorship. There is also a discussion of the feminist movement's embrace of this author, the fact that her life and work have become the focus of tourist attractions, the publishing practices associated with her books and the main challenges involved in translating the works.

Keywords: Translation. Index Librorum Prohibitorum. Censorship. La mare au diable. Un hiver à Majorque. La petite Fadette.

\section{Introducción}

La escritora George Sand (1804-1876), seudónimo de Aurore Dupin, encarnó un modelo de mujer independiente y emancipada, anticlerical, crítica con el matrimonio y simpatizante de las ideas socialistas. La inmensa notoriedad de sus obras literarias y de su agitada vida privada la convirtieron en un personaje público tanto en Francia como en España. Ocho años después de la publicación de su primera novela y en plena efervescencia creativa de la autora, el tribunal de la Sacra Congregatio Indicis incluyó uno de sus libros, Lélia, en el Index Librorum Prohibitorum del Vaticano. Al año siguiente, en 1841, se añadieron once más y todavía otro en 1842. Todos ellos fueron desaprobados por amatorios con algunos aspectos doctrinales coyunturales. En 1863, a los motivos morales y doctrinales se añadieron razones ideológicas y se censuró la obra completa escrita hasta el momento, opera omnia, a causa del carácter socialista de algunas de sus novelas.

Se tradujeron al castellano treinta y seis de sus novelas en vida de la autora y las reediciones y retraducciones se han sucedido hasta nuestros días ${ }^{1}$. Hoy contamos con una cincuentena de sus obras en español y con cinco títulos en catalán. El caso de George Sand es excepcional y la recepción de sus obras en España ha sido estudiada extensamente, entre otros, por Montesinos (1955), Colonge (1977), Brown (1988), Aymes (1997), Santa (2006), Figuerola (2008), Alonso Seoane (2015), Sánchez García (2016) y Riba y Sanmartí (2020).

En este artículo nos centraremos en las distintas ediciones y (re)traducciones ${ }^{2}$-es decir las distintas traducciones de las que disponemos de una obra a una misma lengua- de La mare au diable, Un hiver à Majorque y La

\footnotetext{
${ }^{1}$ Para la recepción en general de la autora en España nos remitimos al artículo «La recepción de George Sand en España: traducciones y censura (1836-1975)», concretamente a la tabla en la que se recogen todas las obras de George Sand vertidas al español entre 1836 y 1975 (Riba y Sanmartí, 2020).

${ }^{2}$ Este artículo se enmarca en las actividades del grupo de investigación consolidado «Estudios de Género: Traducción, Literatura, Historia y Comunicación» (GETLIHC, 2017, SGR 136) de la Universitat de Vic-Universitat Central de Catalunya, del proyecto I+D+i «Traducción y censura: género e ideología (1939-2000)» (ref.: FFI2014-52989-C2-2-P), financiado por el Ministerio de Economía y Competitividad, y de la «Red de Estudios y Datos sobre la Edición Iberoamericana y Transnacional (RED-EDIT)» (ref.: RED2018-102343-T) que financia el Ministerio de Ciencia, Innovación y Universidades.
} 
petite Fadette, tres novelas con versiones en catalán ${ }^{3}$ y castellano ${ }^{4}$, con trayectorias muy distintas a lo largo de más de un siglo. El criterio de selección no responde a su representatividad sino al hecho de que son las únicas traducidas al español y al catalán, de modo que podemos seguir y comparar las vicisitudes de las obras en ambas lenguas y ahondar en las complejas relaciones entre el sistema literario español y el catalán, separados pero interrelacionados. Además, la suerte de las tres obras es muy dispar, lo que permite constatar que los factores y agentes que entraron en juego a la hora de promover u obstaculizar las reediciones y retraducciones, las llamadas «voces contextuales» (Alvstad y Assis Rosa, 2015: 3), fueron de diversa índole en función de las obras. Las preguntas que nos proponemos contestar son las siguientes:

¿Qué editoriales publicaron los libros y qué traductores o traductoras vertieron esas obras al castellano y al catalán? ¿Qué impacto tuvo la inclusión de la autora en el Index en la recepción de las obras? ¿Afectó la censura previa durante el franquismo a los tres libros que nos ocupan? ¿Qué aspectos de las novelas han suscitado más interés y qué factores han determinado su trayectoria editorial? ¿Se señala en prólogos o en estudios algún reto de traducción en particular? ¿Por qué motivos se retraducen estas novelas?

Para responder a estas cuestiones hemos confeccionado dos tablas para cada una de las obras, una con las distintas ediciones y traducciones al español y otra al catalán ${ }^{5}$. El análisis de las tablas permite identificar las fluctuaciones en la publicación y detectar si la inclusión de la autora en el Index tuvo algún impacto en su trayectoria. A fin de determinar si las editoriales tuvieron problemas para publicar estas obras durante el franquismo hemos consultado todos los informes de censura sobre ellas custodiados en el Archivo general de la Administración (AGA), sito en Alcalá de Henares.

Asimismo, con el propósito de señalar las cuestiones que han despertado la curiosidad por las tres obras de Sand y los factores que han propiciado que la autora se mantuviera presente en la esfera pública nos remitimos a varias fuentes. En primer lugar, hemos analizado los textos que acompañan las distintas ediciones y traducciones. Su estudio nos proporciona información sobre el contexto en que aparecieron, lo que la crítica señala como aportaciones de la obra, la percepción social de la escritora a lo largo del tiempo, etc.

\footnotetext{
${ }^{3}$ También está traducido al catalán el relato juvenil Histoire du veritable Gribouille por Joan Leita con el título de La veritable història d'en Sucapà, e Histoire de ma vie, una obra autobiográfica, en versión de Caterina Calafat titulada Història de la meva vida.

${ }^{4}$ Nos hemos centrado en editoriales españolas o que solicitaran autorización para introducir libros en España durante el franquismo.

${ }^{5}$ Las tablas se han elaborado a partir de los fondos bibliográficos de la Biblioteca Nacional de España, la Biblioteca de Cataluña, el Catálogo Colectivo de las Universidades de Cataluña y el Catálogo de la Red de Bibliotecas de la Diputación de Barcelona, y se ha consultado la bibliografía que aparece en la obra de George Sand Un hivern a Mallorca seguit de l'epistolari de la turista George Sand, con traducción de Antoni-Lluc Ferrer (Barcelona, Edicions de 1984, colección «La Clàssica», 5).
} 
En segundo lugar, con el objetivo de analizar qué aspectos contribuyeron a popularizar a la autora y alinearon a Sand con los intereses comerciales de la industria editorial, hemos examinado también las noticias que aparecieron sobre la novelista en La Vanguardia. Si bien ya se ha estudiado la recepción de Sand en otras publicaciones periódicas ${ }^{6}$, La Vanguardia es un periódico de gran tirada, de venta en todo el Estado, con una amplia sección cultural y que se ha publicado ininterrumpidamente desde 1881 hasta la actualidad ${ }^{7}$. En este largo período de tiempo, se menciona su nombre en más de 1500 ocasiones que sirven de barómetro de su popularidad. Sus constantes apariciones en La Vanguardia demuestran la presencia pública de la autora, lo que se traduce en interés por parte del público lector $\mathrm{y}$, consecuentemente, de las editoriales en publicarla.

Finalmente, hemos rastreado prólogos y notas del traductor o traductora para indagar las principales dificultades de traducción y la justificación de determinadas decisiones, así como las razones que empujaron a retraducir dos de las tres novelas estudiadas.

\section{Ediciones, retraducciones y censura}

\subsection{La mare au diable}

La mare au diable se publicó por entregas en el Courrier Français en 1845 y apareció en 1846 en un volumen junto con Les noces de Campagne. El libro narra la historia de Germain, un joven y robusto granjero, que, después de enviudar y presionado por su suegro, se propone casarse con una viuda rica de un pueblo cercano. Cuando Germain va a visitar a la mujer, conoce a una humilde y virtuosa pastora, Marie. Durante el viaje se enamoran y la acaba desposando.

En una nota introductoria, la propia Sand explica que su objetivo con este texto es retratar literariamente el ambiente de los grabados de Holbein centrándose en los trabajadores del campo y dando voz a personajes sencillos. Esta breve novela fue la primera en traducirse al castellano de las tres obras que trataremos. Cuenta con diez ediciones en español entre 1855 y 2001 y una en catalán de 1955. Las traducciones al español son de Amparo F. Villegas, Carlos de Arce y Matilde Santos, y al catalán, de Just Cabot.

Tabla 1: Traducciones al español de La mare au diable

\footnotetext{
${ }^{6}$ La presencia de Sand en la prensa española ha sido estudiada, entre otros, por Brown (1988), Solà (2006) y Vicens-Pujol (2008). Concretamente, Solà ha examinado el tratamiento de la muerte de Sand, en 1876, en Diario de Cataluña, La Imprenta y La Crónica de Cataluña. Brown recoge noticias sobre la autora procedentes de las publicaciones periódicas El Semanario pintoresco español, La Censura, La Esperanza, La España y La Época, desde la década de 1830 hasta finales del siglo XIX. Vicens Pujol trata la recepción de la autora en La Palma. Semanario de Historia y de literatura; Revista de Madrid; Almacén de frutos literarios. Semanario de Palma; El día; Última hora; Las provincias; Baleares y El Correo catalán. Las primeras noticias son de 1841y las últimas corresponden al año 1975.

${ }^{7}$ La Vanguardia se encuentra entre los cinco periódicos más antiguos de España que todavía se publican. Los cuatro anteriores son: Faro de Vigo (1853), El Norte de Castilla (1854), Las Provincias (1866) y Diario de Cádiz (1867). De todos ellos, La Vanguardia es el que ha tenido más difusión en el conjunto del Estado español.
} 


\begin{tabular}{|c|l|l|l|l|l|}
\hline Año & Ciudad & \multicolumn{1}{|c|}{ Editorial } & \multicolumn{1}{|c|}{ Traductor/a } & Colección & Prólogo \\
\hline 1855 & Madrid & $\begin{array}{l}\text { Impr. de la Sobe- } \\
\text { ranía Nacional }\end{array}$ & (No consta) & & \\
\hline 1868 & Barcelona & $\begin{array}{l}\text { Imprenta de la } \\
\text { Corona }\end{array}$ & (No consta) & & \\
\hline 1934 & Madrid & Revista Literaria & $\begin{array}{l}\text { Amparo F. Ville- } \\
\text { gas }\end{array}$ & $\begin{array}{l}\text { Novelas y } \\
\text { Cuentos }\end{array}$ & \\
\hline 1940 & Madrid & Dédalo & (No consta) & & $\begin{array}{l}\text { Ángeles Car- } \\
\text { dona }\end{array}$ \\
\hline 1969 & Barcelona & Bruguera & Carlos de Arce & & $\begin{array}{l}\text { Ángeles Car- } \\
\text { dona }\end{array}$ \\
\hline 1972 & Barcelona & Bruguera & Carlos de Arce & & $\begin{array}{l}\text { Ángeles Car- } \\
\text { dona }\end{array}$ \\
\hline 1973 & Barcelona & Bruguera & Carlos de Arce & & $\begin{array}{l}\text { Ángeles Car- } \\
\text { dona }\end{array}$ \\
\hline 1974 & Barcelona & Bruguera & Carlos de Arce & & \\
\hline 1989 & Madrid & Cátedra & Matilde Santos & $\begin{array}{l}\text { Letras Uni- } \\
\text { versales }\end{array}$ & \\
\hline 2001 & Barcelona & Seuba (1. ${ }^{\text {a ed. })}$ & Carlos de Arce & Prisma & \\
\hline
\end{tabular}

\begin{tabular}{|c|c|l|l|c|c|}
\hline \multicolumn{7}{|c|}{ Tabla 2: Traducciones al catalán de La mare au diable } \\
\hline Año & Ciudad & Editorial & Traductor & Colección & Prólogo \\
\hline 1955 & Perpiñán & Proa & Just Cabot & A tot vent & Just Cabot \\
\hline
\end{tabular}

La inclusión en el Index no parece haber influido en la trayectoria editorial de esta obra. El efecto más visible de la condena tuvo lugar después de que el Vaticano incluyera trece de sus novelas en el Index Librorum Prohibitorum entre 1840 y 1842 . Aunque las traducciones al español se redujeron entonces drásticamente y durante la década de 1850 solo se tradujeron tres novelas, una de las que se publicó fue La charca del diablo.

Durante el franquismo, se autorizó la publicación de la obra en castellano. Existe una edición de 1940 de la cual no consta informe de censura. Los informes de $1969^{8}, 1972^{9}$ y $1974^{10}$ fueron positivos y la novela se reeditó tres veces en la Editorial Bruguera. Recordemos que en 1966 se aprobó una nueva Ley de Prensa, conocida como Ley Fraga, que dio fin a la censura previa obligatoria. Someterse al examen de los censores pasó entonces a ser voluntario. Sin embargo, muchas editoriales continuaron enviando sus originales al Ministerio de Información y Turismo, porque cabía la posibilidad de que se secuestraran obras ya distribuidas si, una vez publicadas, los censores las consideraban inapropiadas. Después de la muerte del dictador se hizo una nueva traducción de La mare au diable a cargo de Matilde Santos y el libro se ha reeditado dos veces más.

El proceso de publicación de la traducción al catalán en pleno régimen, por su parte, fue muy dificultoso y finalmente se editó en el sur de Francia en 1955, en

\footnotetext{
${ }^{8}$ AGA: IDD (03)050.000, 66/03024-4518.

${ }^{9}$ AGA: IDD (03)050.000, 73/02470-12613.

${ }^{10}$ AGA: IDD (03)050.000, 73/04122-5956.
} 
la colección «A tot vent» de Edicions Proa. Es importante recordar que a la censura ideológica debemos añadir en ese caso la censura idiomática (Bacardí, 2012: 12). La edición catalana y las traducciones al catalán estuvieron categóricamente prohibidas de 1939 a 1945 (Gallofré, 1991: 208), y el veto a esta lengua no se levantó hasta 1962, con la política aperturista de Fraga Iribarne (Bacardí 2012: 50). «A tot vent», colección inaugurada en 1928, publicaba tanto novelas catalanas como obras de la literatura universal traducidas al catalán por personalidades de prestigio (entre otros, por Josep Carner o Andreu Nin). La colección, dirigida por Joan Puig i Ferrater hasta que se interrumpió en 1938 a causa de la Guerra Civil (con ochenta y dos títulos en el catálogo), se retomó en 1951 en el exilio, en Perpiñán. Asumió entonces su dirección uno de los fundadores de Edicions Proa, Josep Queralt, que llegó hasta el número 100 (Llecha, 2009: 164-165). Estas circunstancias explican que la traducción del libro tardase años en ver la luz, tal como relata Just Cabot (1955: 5) en el prólogo: «Els esdeveniments han fet que aquesta traducció dormís una colla d'anys en els calaixos de l'editor».

En 1961, la Comercial Librera Hispano-Francesa, de Barcelona, solicitó la importación de cincuenta ejemplares de L'Estany del diable, que se autorizó en 1962. El censor asevera que la obra «no es recomendable, pero no está incluida en el Index» ${ }^{11}$. Es importante precisar que la novela no forma parte del listado de los trece títulos de Sand específicamente prohibidos en el Index.

\subsection{Un hiver à Majorque}

Un hiver à Majorque relata las vicisitudes de un viaje a Mallorca. Apareció por primera vez por entregas en la Revue des Deux Mondes a lo largo de 1841 y fue publicado al año siguiente como libro por la editorial Souverain. La voz del narrador es masculina (como el seudónimo), pero la obra se inspira en la estancia de George Sand y Frédéric Chopin en la isla en la que residieron de noviembre de 1838 a febrero de 1839, junto con los dos hijos de Sand, Maurice y Solange. Aunque incide en la belleza inusitada de un paraje privilegiado, el narrador muestra su desazón por un sinfín de motivos, desde los mosquitos, el aceite de oliva infame, la falta de higiene y el estado deplorable de las carreteras hasta la inhospitalidad de los lugareños.

El libro se introdujo en España en 1902 en traducción de Pedro Estelrich (con el título de Un invierno en Mallorca). Desde entonces se ha publicado en veintidós editoriales y reeditado más de cuarenta veces en ocho traducciones distintas al castellano, la más reciente de 2016. Nos constan asimismo tres traducciones al catalán, de las que se han hecho seis ediciones en cuatro editoriales. Es el libro más retraducido de esta autora tanto al castellano como al catalán, lo que consolida su valor de clásico, puesto que las retraducciones son una forma de canonizar (Venuti, 2004).

\begin{tabular}{|c|c|c|c|c|c|}
\hline \multicolumn{6}{|c|}{ Tabla 3: Traducciones al español de Un hiver à Majorque } \\
\hline Año & Ciudad & Editor & Traductor/a & Colección & $\begin{array}{c}\text { Prólogo / } \\
\text { Epílogo }\end{array}$ \\
\hline
\end{tabular}

${ }^{11}$ AGA: IDD (03)050.000 66/6426-137. 


\begin{tabular}{|c|c|c|c|c|c|}
\hline \multicolumn{6}{|c|}{ Tabla 3: Traducciones al español de Un hiver à Majorque } \\
\hline 1902 & Palma de M. & Bartolomé Rotger & Pedro Estelrich & & $\begin{array}{l}\text { Gabriel } \\
\text { Alomar }\end{array}$ \\
\hline 1932 & Palma de M. & $\begin{array}{l}\text { Imprenta de José } \\
\text { Tous }\end{array}$ & Pedro Estelrich & & $\begin{array}{l}\text { Gabriel } \\
\text { Alomar }\end{array}$ \\
\hline 1934 & Madrid & Espasa-Calpe & Carmen Gallardo & $\begin{array}{l}\text { Colección } \\
\text { Universal }\end{array}$ & \\
\hline 1943 & Buenos Aires & Poseidón & Francisco Madrid & Pandora & $\begin{array}{l}\text { Francisco } \\
\text { Madrid }\end{array}$ \\
\hline 1949 & Palma de M & Clumba & B. Payeras & & \\
\hline 1951 & Palma de M. & Clumba & B. Payeras & & \\
\hline 1958 & Barcelona & Mateu & Tello Casán & $\begin{array}{l}\text { Biblioteca } \\
\text { Mateu }\end{array}$ & \\
\hline 1964 & Barcelona & Mateu & Tello Casán & $\begin{array}{l}\text { Todo para } \\
\text { muchos }\end{array}$ & \\
\hline 1969 & Madrid & Edaf & Enrique Azcoaga & $\begin{array}{l}\text { Biblioteca } \\
\text { Edaf }\end{array}$ & \\
\hline 1971 & Palma de M. & Clumba & B. Payeras & & \\
\hline 1974 & Palma de M. & $\begin{array}{l}\text { Imprenta M. Al- } \\
\text { cover }\end{array}$ & Luis Ripoll & & Luis Ripoll \\
\hline 1975 & Palma de M. & Clumba & $\begin{array}{l}\text { Trad. directa del } \\
\text { original manuscri- } \\
\text { to. B. Payeras }\end{array}$ & & \\
\hline 1975 & Palma de M. & $\begin{array}{l}\text { Edicions La Car- } \\
\text { toixa }\end{array}$ & B. Payeras & & \\
\hline 1978 & Madrid & Edaf & Enrique Azcoaga & & \\
\hline 1979 & Palma de M. & $\begin{array}{l}\text { Luis Ripoll Editor } \\
\left(2 .^{a} \text { ed.) }\right.\end{array}$ & Luis Ripoll & & \\
\hline 1981 & Madrid & Edaf & Enrique Azcoaga & $\begin{array}{l}\text { Biblioteca } \\
\text { Edaf de Bolsi- } \\
\text { llo }\end{array}$ & \\
\hline 1983 & Palma de M. & Luis Ripoll Editor & Luis Ripoll & & \\
\hline 1985 & Palma de M. & $\begin{array}{l}\text { Miquel Font (1. } \\
\text { ed.) }\end{array}$ & (No consta) & $\begin{array}{l}\text { Biblioteca } \\
\text { Grandes Éxitos }\end{array}$ & $\begin{array}{l}\text { Valentí } \\
\text { Puig }\end{array}$ \\
\hline 1988 & Palma de M. & Luis Ripoll Editor & Luis Ripoll & & Luis Ripoll \\
\hline 1989 & Barcelona & Orbis & Pedro Estelrich & $\begin{array}{l}\text { Biblioteca } \\
\text { Grandes Escri- } \\
\text { toras } \\
\text { Biblioteca } \\
\text { Grandes Éxitos }\end{array}$ & \\
\hline 1990 & Madrid & Edaf & Enrique Azcoaga & & \\
\hline 1991 & Palma de M. & $\begin{array}{l}\text { Miquel Font }\left(2 .^{\mathrm{a}}\right. \\
\text { ed.) }\end{array}$ & (No consta) & & $\begin{array}{l}\text { Valentí } \\
\text { Puig }\end{array}$ \\
\hline 1992 & Palma de M. & Miquel Font & (No consta) & & \\
\hline 1992 & Palma de M. & Omnisa & Luis Ripoll & & \\
\hline 1995 & Palma de M. & Luis Ripoll Editor & Luis Ripoll & & Luis Ripoll \\
\hline 1997 & Palma de M. & Ingrama & B. Payeras & & \\
\hline 1997 & Palma de M. & Olañeta & Marcel Planas & $\begin{array}{l}\text { La Foradada, } \\
41\end{array}$ & $\begin{array}{l}\text { Robert } \\
\text { Graves }\end{array}$ \\
\hline 1997 & Palma de M. & Olañeta & Marcel Planas & $\begin{array}{l}\text { Terra Incogni- } \\
\text { ta, } 15\end{array}$ & \\
\hline
\end{tabular}




\begin{tabular}{|c|c|c|c|c|c|}
\hline \multicolumn{6}{|c|}{ Tabla 3: Traducciones al español de Un hiver à Majorque } \\
\hline 1998 & Meudt & $\begin{array}{l}\text { Classic Collection } \\
\text { Carolina }\end{array}$ & $\begin{array}{l}\text { Josep Moll Mar- } \\
\text { quès }\end{array}$ & & $\begin{array}{l}\text { (Prólogo } \\
\text { sin firmar) }\end{array}$ \\
\hline 1999 & Palma de M. & Cort (1. ${ }^{\mathrm{a}}$ ed.) & (No consta) & & \\
\hline 2000 & Palma de M. & Olañeta (2. ${ }^{\mathrm{a}}$ ed.) & Marcel Planas & $\begin{array}{l}\text { Terra Incogni- } \\
\text { ta, } 15\end{array}$ & $\begin{array}{l}\text { Robert } \\
\text { Graves }\end{array}$ \\
\hline 2001 & Pollensa & P\&C Manus & $\begin{array}{l}\text { Trad. actualizada } \\
\text { por Josep Moll } \\
\text { Marquès }\end{array}$ & $\begin{array}{l}\text { Classic Collec- } \\
\text { tion Carolina }\end{array}$ & \\
\hline 2001 & Palma de M. & Olañeta & Marcel Planas & & $\begin{array}{l}\text { Robert } \\
\text { Graves }\end{array}$ \\
\hline 2003 & Pollensa & $\begin{array}{l}\text { P\&C Design (3. } \\
\text { ed.) }\end{array}$ & $\begin{array}{l}\text { Trad. actualizada } \\
\text { por Josep Moll } \\
\text { Marqués }\end{array}$ & $\begin{array}{l}\text { Classic Collec- } \\
\text { tion Carolina }\end{array}$ & \\
\hline 2004 & Palma de M. & Cort $\left(2 .^{a}\right.$ ed. $)$ & (No consta) & & \\
\hline 2005 & Palma de M. & $\begin{array}{l}\text { Classic Collection } \\
\text { Carolina }\end{array}$ & $\begin{array}{l}\text { Josep Moll Mar- } \\
\text { quès }\end{array}$ & & \\
\hline 2006 & Pollensa & $\begin{array}{l}\text { Classic Collection } \\
\text { Carolina }\end{array}$ & $\begin{array}{l}\text { Josep Moll Mar- } \\
\text { quès }\end{array}$ & & \\
\hline 2007 & Palma de $\mathrm{M}$. & Olañeta & Marcel Planas & $\begin{array}{l}\text { Terra Incogni- } \\
\text { ta }\end{array}$ & $\begin{array}{l}\text { Robert } \\
\text { Graves }\end{array}$ \\
\hline 2009 & Barcelona & RBA & Enrique Azcoaga & $\begin{array}{l}\text { Biblioteca } \\
\text { Grandes Escri- } \\
\text { toras }\end{array}$ & $\begin{array}{l}\text { Carme } \\
\text { Riera }\end{array}$ \\
\hline 2010 & Barcelona & RBA & $\begin{array}{l}\text { Enrique Azcoaga } \\
\text { (cedida por Edaf) }\end{array}$ & & $\begin{array}{l}\text { Carme } \\
\text { Riera }\end{array}$ \\
\hline 2011 & Muro & $\begin{array}{l}\text { Classic Collection } \\
\text { Carolina }\end{array}$ & $\begin{array}{l}\text { Josep Moll Mar- } \\
\text { quès }\end{array}$ & & \\
\hline 2016 & Palma de M. & Bilibú D.L. & (No consta) & & \\
\hline 2016 & Palma de M. & $\begin{array}{l}\text { Classic Collection } \\
\text { Carolina }\end{array}$ & $\begin{array}{l}\text { Josep Moll Mar- } \\
\text { quès / } \\
\text { Aina Sampol Va- } \\
\text { llespir }\end{array}$ & & \\
\hline
\end{tabular}

\begin{tabular}{|c|c|c|c|c|c|}
\hline Año & Ciudad & Editorial & Traductor/a & Colección & $\begin{array}{c}\text { Prólogo / } \\
\text { Epílogo }\end{array}$ \\
\hline 1992 & Barcelona & Edhasa (1. ${ }^{\mathrm{a}}$ ed.) & Marta Bes & $\begin{array}{l}\text { Clàssics i } \\
\text { Moderns }\end{array}$ & $\begin{array}{l}\text { Antoni } \\
\text { Marí / } \\
\text { Robert } \\
\text { Graves }\end{array}$ \\
\hline 1993 & Mallorca & Moll & $\begin{array}{l}\text { Jaume Vidal Al- } \\
\text { cover }\end{array}$ & Tomir & $\begin{array}{l}\text { Jaume } \\
\text { Vidal Al- } \\
\text { cover }\end{array}$ \\
\hline 2004 & Barcelona & Proa (1. ${ }^{\mathrm{a}}$ ed. $)$ & Marta Bes & A tot vent & $\begin{array}{l}\text { Antoni } \\
\text { Marí / } \\
\text { Robert } \\
\text { Graves }\end{array}$ \\
\hline 2009 & Barcelona & Edicions 62 (1. ${ }^{\mathrm{a}}$ ed.) & Marta Bes & Lectura+ & \\
\hline 2013 & Barcelona & $\begin{array}{l}\text { Edicions de } 1984\left(1 .^{\text {a }}\right. \\
\text { ed.) }\end{array}$ & $\begin{array}{l}\text { Antoni-Lluch } \\
\text { Ferrer }\end{array}$ & La Clàssica & $\begin{array}{l}\text { Antoni- } \\
\text { Lluch Fe- } \\
\text { rrer }\end{array}$ \\
\hline
\end{tabular}




\begin{tabular}{|c|c|c|c|c|}
\hline 2017 & $\begin{array}{l}\text { Palma de } \\
\text { M. }\end{array}$ & $\begin{array}{l}\text { Institució de Borja } \\
\text { Moll ( } 2 .^{a} \text { ed.) }\end{array}$ & $\begin{array}{l}\text { Jaume Vidal Al- } \\
\text { cover }\end{array}$ & $\begin{array}{l}\text { Jaume } \\
\text { Vidal Al- } \\
\text { cover }\end{array}$ \\
\hline
\end{tabular}

Como puede observarse en las tablas 3 y 4, a diferencia de otros libros de Sand, las reediciones de Un invierno en Mallorca se han sucedido a lo largo de más de un siglo, aunque cabe señalar que se tradujo al español treinta y nueve años después de su publicación, cuando los protagonistas que inspiraron la novela ya habían fallecido. Es lo que Vanderschelden (2000: 9) considera una «traducción fría». Uno de los motivos que facilitó la publicación de la obra fue el hecho de que Un hiver à Majorque, que ya se había publicado cuando se hicieron las primeras condenas, no fuese una novela amatoria y no se mencionara en la lista de libros prohibidos.

Durante el franquismo, la censura previa no se ensañó con este libro y la obra pudo reeditarse diez veces. Es importante apuntar, sin embargo, que en $1938^{12}$ se prohibió la introducción en edición popular solicitada por Espasa-Calpe y que, aunque se aprobaron las solicitudes de $1944^{13}, 1945^{14}$ y $1949^{15}$, se denegó de nuevo su publicación en $1952^{16}$. En el informe consta lo siguiente: «Aunque no es estrictamente una obra amatoria, por lo que queda excluida del decreto del Index, creo, sin embargo, que, por continuos ataques y frases despectivas hacia los españoles, su fe y sus creencias, no debe ser autorizada tal obra». En diciembre de 1953 se ordenó además la retirada de todos los ejemplares que se hallaban en circulación. Fue el único revés editorial importante, puesto que a partir de ese año los encargados de los informes de censura consideraron que la obra no atacaba al Dogma, ni a la Iglesia, ni a sus Ministros ni a la Moral $^{17}$. Las nuevas traducciones al castellano en época franquista se encargaron a Francisco Madrid, B. Payeras, Tello Casán, Enrique Azcoaga y Luis Ripoll. Con posterioridad al advenimiento de la democracia, se publicaron dos traducciones más a cargo de Marcel Planas y Josep Moll.

La primera versión catalana no apareció hasta 1992 y la más reciente es de 2017. Los responsables de las traducciones son Marta Bes, Jaume Vidal Alcover y Antoni-Lluch Ferrer.

\subsection{La petite Fadette}

La petite Fadette apareció en forma de folletín en la publicación periódica republicana Le Crédit y se presentó en un solo volumen en 1849 en la editorial Michel Lévy Frères. La novela explica los amores entre Landry Barbeau, hijo de campesinos, y Fanchon Fadette, una chica que vive con su abuela en condiciones

\footnotetext{
${ }^{12}$ AGA: IDD (03)050.000, 21/07062-91.

13 AGA: IDD (03)050.000, 21/07536-6551.

${ }^{14}$ AGA: IDD (03)050.000, 21/07684-4080.

15 AGA: IDD (03)050.000, 21/08887-5218.

${ }^{16}$ AGA: IDD (03)050.000, 21/09437-1054.

17 AGA: IDD (03)050.000, 21/12072-3448; IDD (03)050.000, 21/12072-3448; IDD (03)050.000,

21/15121-1880; IDD (03)050.000, 21/18431-7585; IDD (03)050.000, 66/03545-10662.
} 
misérrimas y a la que la comunidad considera una bruja. La pareja tendrá que superar innumerables obstáculos, entre los cuales los recelos de Sylvinet, el hermano gemelo de Landry. Al final, Fanchon demostrará que es honrada y virtuosa, se ganará la estima de los Barbeau y se casará con Landry.

Durante el franquismo, en 1945, la editorial Reguera quiso publicar la obra con el título $\operatorname{Los}_{\text {mellizos }}{ }^{18}$, pero el permiso le fue denegado. Aunque no se precisen las razones del rechazo de una historia de ternura y superación que acaba en boda, suponemos que responde al influjo de la condena vaticana del siglo anterior. Cabe señalar que en varios de los informes de censura de otras obras de Sand en los que sí se especifica el motivo por el cual se deniega la publicación se alega: «incluida en el Índice de los Libros Prohibidos» ${ }^{19}$. La traducción al castellano no llegó hasta 1982, 133 años después de su publicación. Apareció con el título de $L a$ pequeña Fadette en Bruguera, traducida por María Elena de Salas Castellano. La versión catalana de la obra, La fadeta, es de 2006. La traducción es de Cristina Solé Castells y fue publicada por Pagès editors en «Lo Marraco Blau», una colección dedicada a mujeres escritoras, en un contexto de creciente interés por la autora.

\begin{tabular}{|c|c|c|l|l|c|}
\hline \multicolumn{7}{|c|}{ Tabla 5: Traducciones al español de La petite Fadette } \\
\hline Año & Ciudad & Editorial & \multicolumn{1}{|c|}{ Traductora } & Colección & Prólogo \\
\hline 1982 & Barcelona & Bruguera & $\begin{array}{l}\mathrm{M}^{\mathrm{a}} \text { Elena de Salas Caste- } \\
\text { llano }\end{array}$ & Todolibro & \\
\hline
\end{tabular}

\begin{tabular}{|c|c|l|l|l|l|}
\hline \multicolumn{7}{|c|}{ Tabla 6: Traducciones al catalán de La petite Fadette } \\
\hline Año & Ciudad & \multicolumn{1}{|c|}{ Editorial } & \multicolumn{1}{c|}{ Traductora } & \multicolumn{1}{c|}{ Colección } & \multicolumn{1}{c|}{ Prólogo } \\
\hline 2006 & Lérida & $\begin{array}{l}\text { Pagès edi- } \\
\text { tors }\end{array}$ & Cristina Solé Castells & $\begin{array}{l}\text { Lo Marraco } \\
\text { Blau }\end{array}$ & $\begin{array}{l}\text { Cristina Solé } \\
\text { Castells }\end{array}$ \\
\hline
\end{tabular}

\section{Ediciones, retraducciones y censura}

\subsection{La mare au diable}

Ángeles Cardona, la responsable del prólogo de la edición de Bruguera traducida por Carlos del Arce, sostiene que La mare au diable tiene el mérito de inaugurar la tercera época en la obra de Sand. Después de las novelas románticas y de las sociales empieza una nueva fase, la de la novela campestre, caracterizada por el bucolismo y un canto a la tierra. En el extenso estudio que firma Cardona, reeditado cuatro veces -el único texto que acompaña las ediciones en castellano-, explica que la escritora embellece la vida de los más humildes a la vez que pone de relieve las injusticias a las que son sometidos y destaca la capacidad del texto de ensamblar las dos tendencias que coexistían: una conservadora y otra socialista o renovadora.

Las novelas campestres se proponen recoger las tradiciones y rituales de la región. En el apéndice del libro, Sand ([1846] 1989: 144) escribe: «Certaines coutumes sont étranges, si curieuses, que j'espère t'amuser encore un instant, cher

\footnotetext{
${ }^{18}$ AGA: IDD (03)050.000, 21/07630-1848.

${ }^{19}$ AGA: IDD (03)050.000, 21/08445-4599; IDD (03)050.000, 21/09792-617; IDD (03)050.000,

21/08469-4957.
} 
lecteur, si tu permets que je te raconte en détail une noce de campagne». La autora relata con todo lujo de detalles la boda de los protagonistas basándose en las celebraciones que ella había presenciado en su infancia, a las que hace alusión con cierta nostalgia: «Car, hélas ! Tout s'en va. [...] Déjà la moitié des cérémonies celtiques, païennes ou du Moyen Âge, que j'ai vues encore en plein vigueur dans mon enfance, se sont effacées» (Sand, [1846] 1989: 144).

En la sección final se explican las tres jornadas de bodas. Sand recoge las vestimentas, las invitaciones, la música, la ceremonia y el banquete. Es destacable el ritual de la col, símbolo de la fecundidad del himen, que tiene lugar el tercer día y con el que se cierra la novela. Se trata de una representación de origen galo pasado por el tamiz del cristianismo primitivo ${ }^{20}$.

Según la estudiosa Claudette Sarlet (1989: 6-11), el esquema narrativo de La mare au diable bebe de las novelas de caballería y de los cuentos de hadas (sin que lo maravilloso aparezca de forma explícita). Se trata, además, de una novela impregnada de leyendas y creencias, como la que da título a la obra. Señala asimismo la cualidad pictórica de sus descripciones, que atribuye a la intensa relación de la autora con pintores como Delacroix y Calamatta y con el arte en general.

La mare au diable cautivó a Just Cabot, traductor y prologuista de la edición catalana, quien reivindica de forma vehemente a George Sand, una novelista que, en su opinión, había sido olvidada injustamente. El traductor alega en el prólogo que las obras de Sand recorren los grandes debates morales, sociales y literarios del siglo XIX y señala que la escritora tomó la palabra cuando muy pocas mujeres lograron hacerlo (Cabot, 1955: 5-7). Recordemos que tanto la editorial como el traductor elegían cuidadosamente las obras que se publicaban. Just Cabot, que tuvo que exiliarse en París a causa de su compromiso político, sostenía que la elección de las obras y la calidad de las traducciones eran fundamentales para normalizar la literatura catalana (Coll-Vinent, 2011).

\subsection{Un hiver à Majorque}

El éxito de este libro ha sido fulgurante. Según Vicens-Pujol (2008: 259) son las continuas reediciones y retraducciones con sus respectivos prólogos «qui ont fait de cet hiver les vacances les moins réussies et les plus célèbres de l'histoire littéraire». ¿Qué es lo que ha despertado tanta expectación durante tanto tiempo y ha motivado que se haya traducido ocho veces al castellano y tres al catalán?

La estancia de la pareja Sand-Chopin en Mallorca suscitó mucho interés y curiosidad en España. Entre 1881, año de aparición de La Vanguardia, y 1902, la primera traducción del libro al castellano, se publicaron 37 artículos sobre la escri-

\footnotetext{
${ }^{20}$ Una mujer se lamenta de la desgracia que ha supuesto la afición a la bebida de su marido, que ha conducido a toda la familia a la miseria. Mientras el marido duerme a causa de una borrachera, la esposa encuentra una comitiva nupcial que la invita a divertirse. Cuando el marido despierta, la persigue con un garrote para castigar su mala conducta, pero los hombres de la boda se interponen entre ellos para impedirlo. La pareja hace las paces y se van cogidos del brazo. El hombre coge una col y entra en la casa de los novios, lo que representa la prosperidad.
} 
tora, algunos de los cuales destacaban el affaire de Sand con Chopin. Las alusiones a la relación de la escritora con Mallorca se incrementaron después de la traducción del libro y fueron numerosas hasta la Guerra Civil. Una de las noticias apuntaba lo escandaloso e inmoral de la conducta de Sand, percibida prácticamente como una provocación: «¿Qué (hay de) extraño que aquella sociedad timorata no recibiese á los dos ilustres viajeros, unidos por un vínculo irregular y haciendo de ello pública ostentación, según merecía cada uno de por sí?» (La Vanguardia, 23/5/1910: 6).

Otro de los artículos hacía referencia al Mallorquín, el barco que los llevó hasta Palma, señalando que las consecuencias de aquel trayecto eran entonces totalmente impredecibles tanto para los protagonistas como para el propio capitán:

El «Mallorquín» además de ser el primer vapor de la matrícula de Palma, tenía el honor de haber llevado a Mallorca, de modo bastante confortable, a dos grandes figuras del Romanticismo: Jorge Sand y Federico Chopin. [...] El señor Sabater, capitán del buque, lo anotó puntualmente en su libro de pasaje sin darle importancia alguna y sin pensar que pasaría a la historia de la literatura y que sería consultado con interés por figuras como Mauricio Barres, Julio Verne o Maurras (La Vanguardia, 2/1/1931: 7).

La estela literaria que dejaría Un invierno en Mallorca es recogida en otra noticia que lleva por título «Mallorca y el turismo literario», firmada por José María Junoy, en la que se considera la publicación del libro como un punto de inflexión: «El libro de George Sand Un hiver en Majorque, cronológicamente, es, tal vez, el primero de estos libros o testimonios literarios escritos por un extranjero sobre Mallorca» (La Vanguardia, 7/11/1934: 9).

El glamour y la controversia que acompañaban a la escritora francesa y el hecho de que estuviera en la cartuja de Valldemosa con su amante, el también célebre pianista y compositor, transformaron la estancia en legendaria. Puesto que Chopin está presente in absentia -no se le menciona en ningún momento-, la censura no pudo reprocharle esta relación tan poco acorde con la moralidad de su tiempo.

Tal vez el notorio desencuentro entre Sand y los habitantes de Mallorca y el hecho de que algunas personas se mencionen con nombre y apellido frenara inicialmente los proyectos editoriales. Sin embargo, el revuelo sostenido en el tiempo acabó convirtiéndose en uno de sus mayores atractivos, tal como se evidencia en los paratextos. En 1841, el año de aparición de la obra, el joven periodista José María Quadrado, residente en Palma de Mallorca -que más adelante se convertiría en especialista en historia de las islas Baleares-, escribió un artículo de respuesta con el título de «Vindicación» en el que corregía las imprecisiones y falsedades que, a su juicio, se afirmaban en el libro de Sand (Ferrer: 2007). Vidal Alcover (1993: 9) recoge en su texto introductorio de la edición catalana de 1993 que Quadrado sostenía que George Sand era «el més immoral dels escriptors i la més immunda de les dones». 
Es importante apuntar que más adelante, en 1975, Llorenç Villalonga publicó Un estiu a Mallorca, un diálogo con Sand al que se sumaron Gabriel Janer Manila en 2002 y Miquel López Crespí en 2004 (Figuerola, 2009: 242-247). Más de un siglo y medio después, los lugareños contestaban aún a las críticas de su huésped de antaño. El interés por su paso por la isla queda patente también en la celebración en marzo de 2005 del congreso George Sand: L'illa i la Dama de Nohant en la Universidad de las Islas Baleares.

Además de hacerse eco de la polémica, los textos que completan las distintas ediciones aprovechan para contextualizar históricamente el relato y, sobre todo, para puntualizar algunas de las afirmaciones de la autora. Es decir, también se suman a la eterna conversación con la novelista sobre la situación de la isla durante el invierno en el que ella moró allí. Luis Ripoll (1974: 11) comenta, entre otras cuestiones, que Sand llegó a la isla dos años después de las desamortizaciones de propiedades de la Iglesia, razón por la cual pudieron alojarse en una cartuja. En la edición catalana en traducción de Jaume Vidal Alcover, este aporta mucha información a través de notas eruditas a pie de página. Apunta, por ejemplo, en el capítulo en el que explica la destrucción del convento de los dominicos de Mallorca, que muchos de los conventos que acabaron desmantelados en España pertenecían a esa orden, que había sido durante siglos la que ejercía la justicia inquisitorial (Vidal, 1993: 120).

Por último, los prólogos y epílogos de las distintas ediciones también se ocupan de buscar alguna explicación para la inquina mostrada por Sand hacia los habitantes de la isla. Luis Ripoll (1974: 11) lo atribuye en parte al clima de desconfianza generalizado a causa de la guerra carlista que tuvo lugar en territorio peninsular de 1833 a 1840. La isla había recibido un alud de forasteros que huían del conflicto y los isleños recelaban de la población recién llegada. Robert Graves sostiene por su parte que, en un clima familiar enrarecido, la hija de Sand, Solange, tergiversaba lo que decían las personas del entorno para presentar a su madre un panorama aciago y desolador. Y Carme Riera se basa en cartas de la autora para afirmar que Sand nunca pudo perdonar que expulsaran a Chopin de una casa a causa de su tuberculosis, una enfermedad contagiosa y, en aquella época, letal.

Por otra parte, en el año 1969 se estrenó una adaptación cinematográfica dirigida por Jaime Camino, con Lucía Bosé en el papel de Sand. La Vanguardia $(27 / 2 / 1969$, p. 59) recogía la noticia destacando que la interpretación de «la gran actriz de origen italiano» constituiría «un importante hito en su carrera artística».

En las últimas décadas, el interés por Sand proviene, en cierta medida, de la reivindicación de la autora por parte de sectores feministas que, en palabras de Michelle Perrot, ven en George Sand «une femme politique, républicaine puis socialiste, toujours sur la brèche, très engagée dans la République de 1848, réfléchissant sur la démocratie» (apud Keating, 2018), y ha sido incluida en colecciones centradas en la recuperación de grandes escritoras. En el prólogo de Carme Riera, Sand es comparada con las escritoras George Eliot, Fernán Caballero y Víctor Català. Riera (2009: 6) afirma que «George Sand se valió de la pluma como Juana de Arco de la espada para triunfar y su triunfo consistió más que en el éxito literario, que también obtuvo, más que en la fama, que también consiguió, 
en su rabiosa independencia». Es interesante señalar también que en Francia se empezaron a publicar las obras completas de Sand en 2008 en la editorial Honoré Champion. La responsable de la edición de Un hiver à Majorque, que apareció en 2013, es Angela Ryan, experta, entre otros campos, en estudios de la mujer.

\subsection{La petite Fadette}

La petite Fadette, como La mare au diable, forma parte de las novelas campestres que evocan la tierra natal de la autora y que pretenden reproducir e inmortalizar el paisaje humano, las costumbres y tradiciones del campo francés, en pleno proceso de modernización. Berry era entonces una región desfavorecida, con muchas desigualdades y un alto índice de analfabetismo. Se trataba de una región aislada, en la que las clases populares hablaban en patois. En 1833 se aprobó una ley para generalizar la alfabetización -y el aprendizaje del francés-, que obligaba a las poblaciones de más de 500 habitantes a tener una escuela y a remunerar a un instructor. Sin embargo, el padre de familia tenía la potestad de enviar o no a sus hijos a la escuela, y en las regiones pobres como Berry, el ausentismo era muy alto (Cooper-Richet, 2009: 194).

La protagonista, Fanchon, es una chica que tiene poderes curativos y que es menospreciada por la comunidad, que la tilda de bruja. Si bien Sand tiñe la historia de cuento de hadas, en aquella época las mujeres podían ser juzgadas y condenadas por brujería:

Si les feux follets, les guérisseurs et autres sorciers et sorcières sont présents dans La Petite Fadette, ils le sont également dans le quotidien de ces populations comme en témoignent un certain nombre de procès qui ont lieu au Tribunal Civil de Chateauroux, dans les années 1839-1840, pour sorcellerie et exercice illégal de la médecine (Cooper-Richet, 2009: 194).

La relación entre Landry y Fanchon es también uno de los aspectos interesantes de la obra, ya que la pareja encarna un modelo de relación basado en el afecto, la complicidad y el respeto mutuo, muy alejados de la visión hegemónica del momento. Cristina Solé Castells (2006: 8) considera que si bien el libro hace un retrato realista de los espacios y prácticas sociales, los personajes están idealizados. La autora se valió de la joven pareja para defender los valores de igualdad y libertad que se reflejan en toda su obra y que ella puso en práctica en su vida.

\section{Consideraciones sobre la traducción}

\subsection{Traducción, industria editorial y turismo}

La gran cantidad de ediciones y traducciones de Un hiver à Majorque se debe en gran medida al hecho de que George Sand se haya convertido en un reclamo turístico en Mallorca y en un lucrativo negocio. Actualmente los libros de Sand se venden en tiendas de souvenirs con puntos de libro y postales, y se ha instalado una placa con un fragmento del texto de la novela en el mirador de Valldemosa. El conflicto judicial entre las dos sociedades que comparten la propiedad de la cartuja de Valldemosa, resuelto en 2011, es revelador y muestra las irradia- 
ciones del libro en el siglo XXI. Ambas sociedades, para sacar partido del peregrinaje de turistas y curiosos, se adjudicaban la única celda en la que Sand y Chopin se alojaron desde el 15 de diciembre de 1838 hasta el 11 de febrero de $1839^{21}$.

Paradójicamente, la invectiva contra los mallorquines ha proporcionado grandes beneficios a los habitantes de la isla. Es curioso recordar que en el expediente de censura de 1958 firmado por A. Sobejano -que autorizó la publicación de la novela-, el censor afirmaba: «Todo es sucio, pobre, triste, deprimente [...]. No es un libro precisamente para atraer al turismo ${ }^{22}$. En la actualidad, en el caso de Un hiver à Majorque, la industria editorial y el señuelo turístico se retroalimen$\tan$.

El éxito del libro, que gracias al circuito turístico parece tener las ventas aseguradas, ha incentivado que algunas ediciones del libro se hayan concebido como productos de consumo, como lo muestra el hecho de que en cinco de las ediciones españolas $(1985,1991,1992,1999$ y 2016) ni siquiera conste el nombre de la persona responsable de la traducción, práctica muy poco habitual en la traducción literaria.

Por otra parte, algunas editoriales han apostado por un libro cuya popularidad ha convertido en clásico y han distinguido sus ediciones encargando nuevas traducciones a profesionales reconocidos. Asimismo, han otorgado al libro un valor añadido con prólogos y epílogos, en ocasiones a cargo del propio traductor, como en el caso de Luis Ripoll y Jaume Vidal Alcover, o de personalidades del mundo de las letras, como Antoni Marí, Valentí Puig, Robert Graves o Carme Riera. El texto de Graves, traductor de esta obra al inglés (publicada por primera vez en 1956 por Valldemosa Edition en Mallorca), aparece en 2 ediciones, en catalán en 1992 (Edhasa) y en castellano en 1997 (Olañeta), y en sus sucesivas reediciones. Algunas traducciones añaden también una cronología (Marcel Planas), ilustraciones de Maurice Sand, hijo de la escritora (Olañeta), fotos de Mallorca del momento de la edición (Edhasa) y las cartas de Sand en las que se refiere a su estancia en la isla (Edicions de 1984).

Todas las traducciones, tanto en catalán como en castellano, se han reeditado varias veces, excepto las de Carmen Gallardo de 1933 y Francisco Madrid de 1943. En algunos casos nos consta la revisión del texto. La traducción al castellano de Pedro Estelrich de 1902 fue revisada por Virgilio Ortega en 1989, y la de Josep Moll de 1998, lo fue por el propio Moll y por Aina Sampol Vallespir en 2016. La actualización de la traducción -especialmente si se hace casi noventa

\footnotetext{
${ }^{21}$ La parte demandante sostenía que la celda auténtica no era la 3 sino la actual celda 4 -que en el momento de iniciar la demanda es de su propiedad-, que antiguamente correspondía a la celda 3, y, además, que el piano que la otra parte exhibía alegando que era el «pobre piano mallorquín» utilizado por Chopin en realidad había sido construido por Oliver Suau Hermanos con posterioridad a su estancia en Mallorca, por lo que no era el instrumento que el talentoso compositor había tocado. La sentencia falló favorablemente y, aunque se interpuso un recurso de apelación, la Audiencia Provincial dio por probados los alegatos de la parte demandante. Véanse Sentencia 23/2011 del Juzgado de lo Mercantil número 2 de Palma de Mallorca, de 31 de enero de 2011, y Sentencia 332/2011 de la Audiencia Provincial de Palma de Mallorca, de 19 de octubre de 2011.

${ }^{22}$ AGA: IDD (03)050.000, 21/12072-3448.
} 
años después- constituye también uno de los motivos para reeditar la obra. En ninguna de las ediciones hay notas del traductor o traductora ni referencias a las decisiones de traducción. De hecho, se trata de un libro sin grandes dificultades traductológicas.

Es interesante señalar la versatilidad del libro, que -fruto de una perspicaz política editorial- se ha incluido en colecciones muy diversas, como clásico («Clàssics i Moderns» $\mathrm{y}$ «Colección Universal»), dentro de colecciones de mujeres escritoras («Biblioteca Grandes Escritoras») o como libro de viajes («Terra Incognita»).

\subsection{Traducción, tradición y patrimonio cultural}

Uno de los principales atractivos de La mare au diable y La petite Fadette es el uso del patois, mediante el cual Sand pretende inmortalizar una forma de vida que se encuentra en vías de extinción a causa de las transformaciones sociales y económicas acaecidas durante el siglo XIX que conllevarían la uniformización de la lengua. Según la autora, esa homogeneización supone una pérdida: «c'est encore un plaisir s'entendre ces idiotismes pittoresques régner sur le vieux terroir du centre de la France ; d'autant plus que c'est la véritable expression du caractère moqueusement tranquille et plaisamment disert des gens qui s'en servent» (Sand, [1846] 1989: 143). La importancia del dialecto de la región de Berry es puesta de relieve por la narradora en el apéndice de La mare au diable, en el que se disculpa por no haber sabido reproducir con más acierto el habla de los campesinos: «Je te demande pardon, lecteur ami, de n'avoir pas su te la traduire mieux ; car c'est une véritable traduction qu'il faut au langage antique et naï des paysans de la contrée que je chante» (Sand, [1846] 1989: 143).

Ahora bien, el uso del patois supone un reto de traducción importante. En el estudio preliminar de la edición española de Bruguera de La charca del diablo, traducida por Carlos de Arce, Ángeles Cardona (1969: 45) alaba el equilibrio entre el patois y el francés en la versión original, pero señala que «el lector no puede disfrutar en una traducción de la lengua que hablan los personajes».

Las traducciones del libro no reflejan las marcas dialectales -fácilmente identificables en el original, puesto que van en cursiva- y optan las más de las veces por palabras normativas y estandarizadas, que dejan también en cursiva. Debemos tener en cuenta que la neutralización de variedades lingüísticas en la traducción es muy frecuente a causa de la enorme dificultad de encontrar soluciones satisfactorias (Assis Rosa, 2012). Veamos algún ejemplo de las traducciones de Carlos del Arce al español y de Just Cabot al catalán: areau, por ejemplo, forma dialectal de charrue, es traducido por arado al castellano y, al catalán, por arada. La palabra battaison, que corresponde al francés «battage», es vertida al castellano por trillo y al catalán por batuda. Pastoure, bergère en habla de la región de Berry, pasa a pastora tanto en castellano como en catalán. También se neutralizan las formas verbales, $j$ 'ons se estandariza y se convierte en tengo en castellano y en tenim en catalán. Los apéndices finales, en los que se recrean las tradiciones y costumbres de la región, son especialmente interesantes desde el punto de vista de la traducción. Veamos a continuación algunos ejemplos: 
Original La petite Marie n'ayant pas encore reçu les cadeaux de noces, appelés $l i$ vrées... (Sand, [1846] 1989: 145).

del Arce La joven María, no habiendo recibido todavía los regalos de boda, llamados libreas... (Sand, 1969: 175).

Cabot Com que la Marieta encara no havia rebut els presents de noces, anomenats lliurades... (Sand, 1955: 200).

Original …ceci s'appelle l'exploit, c'est-à-dire la lettre de faire-part (Sand, [1846] 1989: 146-147).

del Arce $\quad$...esto se llama la notificación, viene a ser como la tarjeta de participación (Sand, 1969: 176).

Cabot $\quad$...això se'n diu l'exploit, és a dir la lletra de participació (Sand, 1955: 202).

Original Le rôle que joue en Bretagne le bazvalan, le tailleur du village... (Sand, [1846] 1989: 148).

del Arce $\quad$ El papel que representa en Bretaña el brazvalan, el sastre del pueblo... (Sand, 1969: 178).

Cabot $\quad$ El paper que juga el bazvalan, el sastre del poble... (Sand, 1955: 205).

Original _...ce personnage de la comédie s'appelle le géomètre. (Sand, [1846] 1989: 183).

del Arce $\quad$...este personaje de la comedia se llama el geometra (Sand, 1969: 214).

Cabot ...aquest personatge de la comèdia és anomenat geòmetra (Sand, 1955: 258).

Original C'est surtout le dernier charroi, appelé la gerbaude... (Sand, [1846] 1989: 184).

del Arce $\quad$...es, sobre todo, la última carreta, llamada la engavillada... (Sand, 1969: 215).

Cabot És sobretot l'última carretada, anomenada la garbada... (Sand, 1955: 261).

Del Arce y Cabot adaptan a la lengua meta algunos de los términos dialectales (librea, geometra / lliurades, geòmetra) y dejan algunas palabras en el patois original (brazvalan en ambas traducciones y también exploit en la versión catalana). También traducen alguno de los términos (notificación en español y garbada en catalán) y Carlos del Arce fuerza una sustantivación por derivación (engavilla$d a)$.

También en La petite Fadette el arraigo territorial representa un desafío de traducción. Según Cristina Solé Castells (2009: 286), traductora al catalán: «Cet air particulier de la région du Berry que l'utilisation de la langue du pays contribue à donner à son roman disparaît inévitablement dans toute traduction, quelle qu'en soit la langue». En este caso disponemos de un artículo de la traductora al catalán en el que comenta algunas de sus decisiones. Solé Castells afirma que la traducción del vocabulario dialectal no ha supuesto una gran dificultad, puesto 
que existen diccionarios especializados. Señala, sin embargo, que se documentó minuciosamente para poder traducir las prácticas agrícolas y las costumbres de la zona. Explica, por ejemplo, que optó por mantener en francés el nombre del santo en la fiesta de Saint Androche y justifica la traducción de danser la bouré por ballar, sin especificar el tipo de baile tradicional, porque la bouré de Berry era diferente del mismo baile en otras regiones y porque asumió que el público receptor no conocería el baile.

Por otra parte, Cristina Solé Castells explica su preocupación por reflejar el lenguaje de Sand y defiende su opción de incluir en los diálogos palabras obsoletas o en desuso para transportar a los lectores y lectoras al siglo XIX. También expresa su interés por mantener la musicalidad de las cancioncillas que aparecen y aporta algunos ejemplos que ilustran su forma de proceder (Solé Castells, 2009: 286-289).

Una de las particularidades de la traducción al catalán es la traducción del pronombre on por el catalán hom -un arcaísmo-, un recurso que no tiene equivalente en castellano (la cursiva es nuestra):

Original

Au premier moment, on ne faisait point entre eux de différence et on croyait voir un œuf et un œuf. Mais, quand on les avait observés un quart d'heure, on voyait que Landry était une miette plus grand et plus fort (Sand, [1849] 1967: 47).

Solé Castells D'entrada no els diferenciaven i hom creia estar veient dues gotes d'aigua, Però quan hom els havia observat un quart d'hora, hom s'adonava que Landry era un pèl més alt i fort (Sand, 2006: 27).

de Salas Castellano A primera vista había tan poca diferencia entre ellos como entre dos huevos. Pero si se les observaba detenidamente durante un cuarto de hora, se veía que Landry era un poquito más alto y más fuerte (Sand, 1982: 13-14).

Otro aspecto interesante es la traducción del nombre de la protagonista y título de la novela. El apelativo significa duende o hada pequeña y se ha traducido al catalán por fadeta, una palabra normativa, muy parecida fonéticamente a la original, y al español como pequeña Fadette:

Original

[...] il vit la petite-fille de la mère Fadet, qu'on appelait dans le pays la petite Fadette, autant pour ce que c'était son nom de famille que pour ce qu'on voulait qu'elle fût un peu sorcière aussi (Sand, [1849] 1967: 83).

Solé Castells $\quad[\ldots]$ veié la néta de la mare Fadet, la qual hom anomenava a la comarca la Fadeta, tant pel fet que era el seu cognom com perquè hom pensava que era també una mica bruixa (Sand, 2006: 67).

de Salas Castellano Al volverse, vio a la nieta de mamá Fadet, a quien todos llamaban la pequeña Fadette, tanto por su apellido como porque se pensaba que la niña también era un poco bruja (Sand, 1982: 57).

\subsection{La traducción del seudónimo}


Puesto que las traducciones abarcan un abanico temporal considerable, hemos podido constatar una transformación en los gustos y costumbres de las técnicas de traducción. Probablemente, la más visible la encontramos en la plasmación del seudónimo de la autora, que pasa de Jorge Sand a George Sand. La tendencia a «domesticar» (Venuti, 1995: 19-20) los nombres propios de autores extranjeros durante el siglo XIX y parte del XX (Julio Verne, Florencia Barclay, etc.) se invirtió a mediados del siglo pasado. En las ediciones de Un invierno en Mallorca de 1902 y 1934 la autoría se atribuye a Jorge Sand, mientras que en las ediciones posteriores se otorga a George Sand. Lo mismo ocurre con La mare au diable. La traducción de 1934 va firmada por Jorge Sand y las ediciones posteriores a los años sesenta atribuyen la obra a George Sand. Ambas apelaciones convivieron a lo largo del siglo XX. Otras novelas de Sand, como El marqués de Villamar o El caballero Mauprat lucían el nombre españolizado en la cubierta en 1967 y 1969 , respectivamente.

También la crítica se refería a la autora a menudo como Jorge Sand. En 1941 se publicó Chopin y Jorge Sand y otros ensayos de Pío Baroja y, en 1944, Esteban Calle Iturrino escribió El idilio de Valldemosa: Chopin y Jorge Sand en Mallorca. En La Vanguardia, los redactores de las noticias optaron por Jorge Sand o George Sand indistintamente y, aunque pocas noticias se refieren a la autora como Jorge Sand a partir de la década de los setenta (22/12/1972: 4 y 62; 13/7/1975: 53), podemos encontrar un ejemplo de ello en 2005: Anton Maria Espadaler, en un artículo titulado «Víctor y Caterina», alude a la escritora francesa como el «ilustre andrógino Jorge Sand» (La Vanguardia, 19/3/2005: 46).

\section{Conclusiones}

La trayectoria editorial de las tres obras de Sand estudiadas es muy dispar. La mare au diable se publicó en castellano al cabo de nueve años de aparecer el original, se ha reeditado en tres traducciones distintas (la más reciente, de 2001) y dispone de una única versión al catalán, publicada en 1955. La primera traducción al castellano de Un hiver à Majorque no llegó hasta el siglo XX, pero el interés por la obra se ha mantenido hasta nuestros días. Es la más retraducida de todas las obras de la autora tanto en castellano, con ocho versiones distintas, como en catalán, con tres. La traducción de la última de las obras, La petite Fadette, es mucho más reciente y solo disponemos de una traducción al español y una al catalán. No se vertió al español hasta 1982 y no se publicó en catalán hasta el año 2006.

La evolución de las obras de Sand se ha visto determinada por varios condicionantes, entre los cuales destacamos la condena vaticana, la censura franquista, la atención de la prensa, el auge del movimiento feminista y el turismo. Aunque la condena vaticana no afectara especialmente a las tres novelas tratadas (poco reprochables desde el punto de vista de la moral católica), entre la totalidad de las obras de Sand traducidas al español hay lagunas significativas que han dado lugar a una imagen incompleta o inexacta de la autora. El efecto de la censura vaticana es perceptible: no se tradujeron, por ejemplo, muchas de sus obras socia- 
listas (Le Meunier d'Angibault, Le Péché de M. Antoine, etc.) ni abiertamente anticlericales (Mademoiselle La Quintinie).

La censura franquista sí que tuvo impacto en las tres obras estudiadas. Aunque Un hiver à Majorque se publicó diez veces a lo largo del periodo, no pudo ser introducida en edición popular en 1938, se denegó en 1952 y se retiraron los ejemplares en circulación en 1953. La mare au diable en castellano, por su parte, se publicó en 1940 y después en 1966, 1972, 1973, y 1974, es decir, después de la Ley de Prensa. En el tercer caso, la autorización para publicar La petite Fadette en español fue denegada en 1945 y no volvió a solicitarse, con lo que no se publicó durante el franquismo. Es importante señalar que los censores utilizaban el Index Librorum Prohibitorum como obra de referencia y que a menudo se descartaba la publicación con el pretexto de la condena vaticana del siglo anterior. En el caso de Sand, la censura administrativa se relajó a partir de 1960. Si entre 1939 y 1960 solo se publicaron dos obras de Sand, a partir de esta fecha se publicaron siete más.

La doble censura en las traducciones al catalán, ideológica e idiomática, dificultó la introducción de Sand en esta lengua en época franquista. La petite Fadette y Un hiver à Majorque no se tradujeron y la edición en catalán de La mare au diable tuvo que esperar hasta 1962 para introducir tan solo cincuenta ejemplares de la traducción, que se había publicado en el exilio, en Perpiñán, en 1955. La mare au diable fue la única obra de Sand que se publicó en catalán durante este período. Just Cabot, el traductor, pertenecía a un nutrido grupo de intelectuales, editores y políticos comprometidos con la lengua y la cultura catalanas. La traducción de George Sand formaba parte de un ambicioso proyecto que estimaba imprescindible verter al catalán los grandes clásicos para dignificar la literatura catalana y homologarla al resto de literaturas nacionales europeas. La reivindicación del patois por parte de la autora avivó aun más el interés de Cabot por la obra, a causa del paralelismo entre la lengua de Berry y el catalán, vedado y amenazado en época franquista.

Podemos afirmar que la censura que se ejerció sobre estas tres obras fue debida al hecho de que la vida de la autora se considerara poco ejemplar para los cánones de la época y no al contenido en sí. El discurso imperante consideraba que el tipo de mujer que Sand encarnaba no era un modelo idóneo para las españolas, como lo demuestra el hecho de que no se incluyera en ninguna de las colecciones concebidas para mujeres que proliferaron a partir de la décadas de 1920. Ella era una mujer con opinión, que vestía de hombre y ocupaba espacios reservados a los hombres, y siempre encontró la repulsa de los sectores más conservadores y la oposición frontal de la Iglesia.

Sand era más que una escritora. Era una celebridad. Sus amores, rivalidades, pugnas intelectuales y posicionamientos políticos se desenvolvían públicamente, hecho inaudito en una mujer del siglo XIX. Era un modelo de mujer que no dejaba indiferente, vilipendiado desde algunos sectores y admirado por otros. Así, la presencia de Sand en la prensa se debía a motivos muy diversos, que a menudo nada tenían que ver con su producción literaria. Los artículos de La Vanguardia durante este largo período se han hecho eco de las películas basadas en 
novelas de Sand, de las nuevas retraducciones, la han comparado con otras escritoras, etc. El tema más recurrente ha sido el de Sand y Chopin en Mallorca. En general, se ofrece de ella una visión positiva, a diferencia de otras publicaciones como Semanario pintoresco español o Diario de Barcelona, donde aparecen artículos que expresan un odio visceral contra la escritora.

Además de la reticencias que Sand despertó en los círculos más retrógrados, la escritora tuvo que lidiar con la oposición de las feministas de su tiempo. A pesar de sus reivindicaciones políticas e intelectuales, tuvo con ellas fricciones públicas y notorias porque diferían en las prioridades, especialmente en el sufragio femenino, para el que ella creía que ni las mujeres ni la sociedad estaban preparadas. Esta visión de Sand empezó a cambiar en España con el feminismo de la Transición y actualmente se la está recuperado como referente feminista, como constatamos, por ejemplo, en el prólogo de Carme Riera o en el hecho de que se haya publicado en la colección «Biblioteca Grandes Escritoras»y «Lo marraco blau».

Otro factor importante que ha estimulado las retraducciones de Sand, y más concretamente, de Un hiver à Majorque, es el hecho de haberse convertido en un reclamo turístico. Irónicamente, el retrato mordaz y corrosivo de Sand ha reportado muchos ingresos a los isleños. A pesar de las valoraciones negativas de la autora, la comparación entre la Mallorca de Sand y la situación actual pone de manifiesto la evolución de la isla y de sus habitantes y permite observar el abismo entre lo que fue y la actualidad. El interés, a veces morboso, por la obra ha favorecido su retraducción.

Aunque disponemos de pocos comentarios sobre las decisiones de traducción de estas tres obras, podemos atestiguar que uno de los principales retos que ofrecen La mare au diable y La petite Fadette son los localismos y las expresiones del habla de la región de Berry, que, irremisiblemente, se diluyen en el texto meta. También debemos tener en cuenta que, en el caso de La charca del diablo, la distancia temporal entre la primera traducción y la última es de 146 años, y en Un invierno en Mallorca es de 114. Este largo periodo de tiempo motivó que las editoriales encargaran nuevas traducciones o que revisaran aquellas que se reutilizaron en distintas ediciones, lo que ha permitido además actualizar la lengua. Sand es la única escritora francesa del XIX que ha suscitado tanto interés durante tanto tiempo, la más ampliamente traducida, publicada y estudiada. Es un caso que no tiene parangón.

Por otra parte, especialmente en el caso de Un hiver à Majorque, las distintas ediciones se presentan como productos comerciales diferentes, con fotografías, dibujos, cartas, prólogos y epílogos. El hecho de que se haya convertido en una obra icónica y una atracción turística en Mallorca le asegura muchas ediciones más. En algunos casos la traducción sirve como marca distintiva, pero en otras ni siquiera se menciona el nombre de la persona responsable de la traducción, una omisión poco usual que podría deberse al hecho de que se considere el libro como un bien de consumo. En todo caso, las múltiples retraducciones han supuesto la canonización de la obra. 
El interés por estas tres obras de Sand se debe en primer lugar al valor intrínseco de la escritura de Sand, cuyas vívidas descripciones cautivaron incluso a sus más férreos detractores. Es el caso del abad de Béthlem y de Nicolás González Ruiz, autores de catálogos de novelas según la rectitud moral de las mismas, que alababan el estilo de Sand pero condenaban su obra.

Por otra parte, sus novelas son un ambicioso retrato de su tiempo. En ellas afloran las tensiones y los conflictos que caracterizan el siglo XIX: el debate sobre la educación, el papel de la Iglesia en la sociedad, la introducción de ideas socialistas, las consecuencias de los avances tecnológicos, el modelo de familia o la función de la literatura, entre otros. Además, el hecho de que fuera independiente y liberada y de que, siendo mujer, lograra vivir de su pluma -aspectos que, precisamente, se le reprocharon durante décadas- también ha servido de acicate para seguir traduciendo y publicando sus obras.

\section{REFERENCIAS BIBLIOGRÁFICAS}

Alonso SeOANE, M ${ }^{a}$ José (2015): «El contexto literario de las publicaciones de Enrique Gil en El Correo Nacional. Enrique Gil traductor de George Sand», in Valentín Carrera (ed.), Enrique Gil y Carrasco y el Romanticismo: actas del Congreso Internacional, El Bierzo, Andavira y Universidad de León, 387-409.

AlvstAD, Cecilia y Alexandra Assis RosA (2015): «Voice in retranslation. An overview and some trends». Target, 27: 1, 3-24.

ASSIS RoSA, Alexandra (2012): «Translating Place: Language Variation in Translation». Word and Text - A Journal of Literary Studies and Linguistics, 2: 2, 75-97.

AYMES, Jean-René (2004): «L'image de Sand en Espagne (1836-1850)», in Jean-René Aymes y Javier Fernández Sebastián (eds.), Image de la France en Espagne (1808-1850). París, Presses de la Sorbonne Nouvelle, 243-262. URL: https://books.openedition.org/psn/2226.

BACARDÍ, Montserrat (2012): La traducció catalana sota el franquisme. Lleida, Punctum.

BAROJA, Pío (1941): Chopin y Jorge Sand y otros ensayos. Barcelona, Pal-las Bartrés.

BRown, Penny (1988): «The Reception of George Sand in Spain», Comparative Literature Studies, 25: 3, 203-224.

CАвот, Just (1955): «Prefaci», in George Sand, L'Estany del diable. Perpiñán, Proa, 5-7.

CALle ItURRINO, Esteban (1944): El idilio de Valldemosa: Chopin y Jorge Sand en Mallorca. San Sebastián, Gráfico Editora.

CARDONA, Ángeles (1969): «Estudio preliminar», in George Sand, La charca del diablo. Barcelona, Bruguera, 11-51.

Colonge, Chantal (1977): «George Sand en Espagne: ses traductions, ses lecteurs», in Claude Dumas (ed.), Culture et Société en Espagne et en Amérique Latine au XIXe siècle. Lille, Université de Lille III, 49-61.

Coll-VINENT, Sílvia (2011): «Just Cabot», in Montserrat Bacardí y Pilar Godayol (eds.), Diccionari de la traducció catalana. Vic, Eumo Editorial. URL: http://www.visat.cat/diccionari/cat.html. 
COOPER-RicheT, Diana (2009): «Mentalités populaires au temps et au pays de La Petite Fadette». L'Ull Crític, 13, 185-194.

FERRER, Antoni (2007): «George Sand, Un hiver à Majorque et ses deux auberges espagnoles». Cahiers d'études romanes, 17, 361-403.

Figuerola, Carme (2008): «Valentina de George Sand, en traducción de Eugenio de Ochoa (1837)». Alicante, Biblioteca Virtual Miguel de Cervantes. URL: http://www.cervantesvirtual.com/nd/ark:/59851/bmc1g0p3.

Figuerola, Carme (2009): «El eco mallorquín de George Sand». Çédille, revista de $\begin{array}{llll}\text { estudios } & \text { franceses, } & \text { 424-427. }\end{array}$ http://cedille.webs.ull.es/cinco/figuerola.pdf.

GALlOFRÉ I VIRGILI, Maria Josepa (1991): L'edició catalana i la censura franquista (1939-1951). Barcelona, Publicacions de l'Abadia de Montserrat.

GRAVES, Robert (2004): «Apèndix», in George Sand, Un hivern a Mallorca. Traducción de Marta Bes y prólogo de Antoni Marí. Barcelona, Proa, 227-240.

Index Librorum Prohibitorum Ssmi D.N. Leonis XIII iussu et auctoritate recognitus et editus: praemittuntur constitutiones apostolicae de examine et prohibitione librorum. Roma, Typis Vaticanis, 1880.

KEATING, Juliette (2018): «Michelle Perrot (2/2). George Sand, une femme libre en sa maison d'artiste». Mediapart, 26 de diciembre. URL: https://blogs.mediapart.fr/edition/aux-lecteursemancipes/article/211218/michelle-perrot-22-george-sand-une-femme-libre-ensa-maison-d-artiste.

LA VAnguardia (sd): La Hemeroteca de La Vanguardia desde 1881 [Base de datos en línea]. URL: https://www.lavanguardia.com/hemeroteca.

LLECHA, Lluna (2009): «Petite étude sur L'Estany del diable : traduction catalane d'un roman champêtre de George Sand». L'Ull Crític, 13-14, 161-171.

MONTESINOS, José F. (1955): Introducción a una historia de la novela en España en el siglo XIX. Seguida del esbozo de una bibliografía española de traducciones de novelas 1800-1850. Valencia, Castalia.

RIBA, Caterina y Carme SANMARTí (2020): «La recepción de George Sand en España: traducciones y censura (1836-1975)». Quaderns. Revista de Traducció, 27, 2949.

RIERA, Carme (2009): «Prólogo», in George Sand, Un invierno en Mallorca. Traducción de Enrique Azcoaga. Barcelona, RBA, 5-10.

RIPOLL, Luis (1974): «Unas palabras de ambientación»(prólogo), in George Sand, Un invierno en Mallorca. Traducción y notas de Luis Ripoll. Palma de Mallorca, Luis Ripoll Editor, 7-19.

SÁNCHEZ GARCÍA, Raquel (2016). «Eugenio de Ochoa, mediador cultural entre España y Europa». Hispania Nova. Revista de Historia Contemporánea, 14, 291-309.

SAND, George (1955): L'Estany del diable. Traducción de Just Cabot. Perpiñán, Proa.

SAND, George (1967 [1849]): La petite Fadette. París, Garnier-Flammarion.

SAND, George (1955): La charca del diablo. Traducción de Carlos de Arce. Barcelona, Bruguera. 
SAND, George (1982): La pequeña Fadette. Traducción de María Elena de Salas Castellano. Barcelona, Bruguera.

SAND, George (1989 [1846]): La mare au diable. París, Presses Pocket.

SAND, George (1991): La veritable història d'en Sucapà. Traducción de Joan Leita. Barcelona, Barcanova.

SAND, George (2006): La fadeta. Traducción de Cristina Solé Castells. Lérida, Pagès editors.

SAND, George (2010): Història de la meva vida. Traducción de Caterina Calafat. Palma, Edicions UIB.

SANTA, Àngels (2006): «Víctor Balaguer, traductor de George Sand», in Francisco Lafarga y Luis Pegenaute (eds.), Traducción y traductores, del Romanticismo al Realismo, Berlín, Peter Lang, 435-446.

SARLET, Claudette (1989): «Préface», in George Sand, La mare au diable. París, Presses Pocket, 5-18.

SOLÀ, Pere (2006): «La muerte de George Sand en la prensa catalana», in Francisco Lafarga y Luis Pegenaute (eds.), Traducción y traductores, del Romanticismo al Realismo, Berlín, Peter Lang, 519-530.

Solé CASTElls, Cristina (2006): «Introducció», in George Sand, La Fadeta. Lérida, Pagès editors, 5-8.

Sole CASTElls, Cristina (2009): «Traduire George Sand: La petite Fadette». L'Ull Crític, 13-14, 281-289.

VANDERSCHELDEN, Isabelle (2000): «Why Retranslate the French Classics? The Impact of Retranslation on Quality», in Myriam Salama-Carr (ed.), On Translating French Literature and Film II, 1-18. Amsterdam, Rodopi.

VENUTI, Lawrence (1995): The translator's Invisibility. Londres / Nueva York, Routledge.

VenUTI, Lawrence (2004): «Retranslations: The Creation of Value». Bucknell Review, 47: 1, 25-38.

VICENS-PUJOL, Carlota (2008): «La réception d'Un hiver à Majorque en Espagne : la presse, les prologue», in Llorenç Villalonga, Un été à Majorque. ClermontFerrand, Presses universitaires Blaise Pascal.

VIDAL, Jaume (1993): «Pròleg», in George Sand, Un hivern a Mallorca. Traducción, notas y prólogo de Jaume Vidal Alcover. Mallorca, Moll. 